Article

\title{
Preparation, Characterization, and Immuno-Enhancing Activity of Polysaccharides from Glycyrrhiza uralensis
}

\author{
Adila Aipire ${ }^{1}$, Pengfei Yuan ${ }^{1}$, Alimu Aimaier ${ }^{1}$, Shanshan Cai ${ }^{1}$, Mahepali Mahabati ${ }^{1}$, \\ Jun Lu ${ }^{2}$, Tianlei Ying ${ }^{3}$, Baohong Zhang ${ }^{4}$ and Jinyao Li $^{1, *(\mathbb{D})}$ \\ 1 Xinjiang Key Laboratory of Biological Resources and Genetic Engineering, College of Life Science and \\ Technology, Xinjiang University, Urumqi 830046, China; kaskas999@163.com (A.A.); \\ 18690282867m0@sina.cn (P.Y.); alimu15276554161@163.com (A.A.); 18699927521@163.com (S.C.); \\ mahpal13565987204@163.com (M.M.) \\ 2 School of Science, and School of Interprofessional Health Studies, Faculty of Health \& Environmental \\ Sciences, Auckland University of Technology, Auckland 1142, New Zealand; jun.lu@aut.ac.nz \\ 3 Key Laboratory of Medical Molecular Virology of MOE/MOH, Shanghai Medical College, Fudan University, \\ Shanghai 200032, China; tlying@fudan.edu.cn \\ 4 Engineering Research Center of Cell and Therapeutic Antibody, Ministry of Education; School of Pharmacy, \\ Shanghai Jiao Tong University, Shanghai 200240, China; bhzhang@sjtu.edu.cn \\ * Correspondence: ljyxju@xju.edu.cn; Tel.: +86-991-858-3259; Fax: +86-991-858-3517
}

Received: 25 October 2019; Accepted: 11 January 2020; Published: 19 January 2020

check for updates

\begin{abstract}
Glycyrrhiza uralensis is a Chinese herbal medicine with various bioactivities. Three fractions (GUPS-I, GUPS-II and GUPS-III) of G. uralensis polysaccharides (GUPS) were obtained with molecular weights of 1.06, 29.1, and $14.9 \mathrm{kDa}$, respectively. The monosaccharide compositions of GUPS-II and GUPS-III were similar, while that of GUPS-I was distinctively different. The results of scanning electron microscopy, FT-IR, and NMR suggested that GUPS-II and GUPS-III were flaky with a smooth surface and contained $\alpha$ - and $\beta$-glycosidic linkages, while GUPS-I was granulated and contained only $\alpha$-glycosidic linkages. Moreover, GUPS-II and GUPS-III exhibited better bioactivities on the maturation and cytokine production of dendritic cells (DCs) in vitro than that of GUPS-I. An in vivo experiment showed that only GUPS-II significantly enhanced the maturation of DCs. These results indicate that GUPS-II has the potential to be used in combination with cancer immunotherapy to enhance the therapeutic effect.
\end{abstract}

Keywords: Glycyrrhiza uralensis polysaccharides; molecular weight; monosaccharide composition; structural characterization; immuno-enhancing activity

\section{Introduction}

Polysaccharides of natural sources show various bioactivities, such as antitumor [1-3], antioxidant [4,5], immunomodulatory [6,7], and anti-inflammatory effects [8], which are closely correlated with their structures and conformations. Many plant-derived polysaccharides have been extensively studied for immune enhancing effect because of their safety profiles [9]. Polysaccharides can activate macrophages, dendritic cells (DCs), T lymphocytes, B lymphocytes, and natural killer cells to produce immune-related molecules, such as cytokines, antibodies, and complement molecules [10-12]. Recently, several studies have shown that polysaccharides bind to receptors such as Toll-like receptors (TLRs) on the surface of macrophages or DCs to trigger several down-stream signaling pathways to promote immune responses $[13,14]$. It has been reported that the chemical structures and chain conformations of polysaccharides are closely correlated to their biological activities [15]. 
Glycyrrhiza uralensis, a member of the Leguminosae family, has been used to treat various diseases such as phlegm, cough, dyspnea, spasms, and pain in traditional herbal medicine $[16,17]$. A lot of components including triterpene saponins, flavonoids, chalcones, and polysaccharides have been identified from licorice, which exhibit anti-inflammatory, antiviral, antioxidant, antitumor, and immunomodulatory activities [16,18-22]. Polysaccharides are one of the most abundant components in G. uralensis, which show immune-enhancing activity. Our previous study showed that G. uralensis water extract (contained $25 \%$ polysaccharides) enhanced the maturation and function of DCs, and exhibited antitumor efficacy on human papillomavirus (HPV)-DC vaccine [23]. Cheng et al. purified glycyrrhiza polysaccharides and found that the polysaccharides could activate macrophages to increase the pinocytic activity and the production of nitric oxide, interleukin-1 (IL-1), IL-6, and IL-12 [16]. $\mathrm{Wu}$ et al. reported that glycyrrhiza polysaccharide liposomes enhanced the function and cytokine production (IL-2 and interferon- $\gamma$ ) of chicken bone marrow-derived DCs compared with glycyrrhiza polysaccharides [18]. However, the structure-activity correlation of G. uralensis polysaccharides (GUPS) is still elusive.

In this study, we purified three polysaccharide fractions using a DEAE-52 column and named them GUPS-I, GUPS-II, and GUPS-III. The chemical composition, preliminary structural features, and immune-enhancing activities of these polysaccharides were comparatively investigated. This study provides some hints for the correlation between the structure and activity of GUPS or other polysaccharides from natural sources.

\section{Materials and Methods}

\subsection{Chemicals and Reagents}

DEAE-52 cellulose was obtained from GE Healthcare (Uppsala, Sweden). The monosaccharides, comprising ribose (Rib), glucuronic acid (GlcA), glucose (Glc), galactose (Gla), mannose (Man), arabinose (Ara), rhamnose (Rha) and xylose (Xyl), lipopolysaccharide (LPS), active carbon, trifluoroacetic acids (TFA), and FITC-Dextran, were purchased from Sigma-Aldrich (St Louis, MO, USA). T-series dextrans (T-10, T-40, T-70, T-500 and Blue dextran) were purchased from Solarbio (Beijing, China). Fetal bovine serum (FBS) and Penicillin-streptomycin were purchased from MRC (Changzhou, China). Medium RPMI-1640 and phosphate-buffered solution (PBS) were purchased from Gibco (Grand Island, NY, USA). Granulocyte-macrophage colony-stimulating factor (GM-CSF) was purchased from PeproTech (Rocky Hill, NJ, USA). The other chemical reagents were purchased from Tianjin Fuchen (Tianjin, China).

The antibodies for flow cytometry comprising anti-CD40-APC, anti-CD86-APC, anti-CD11c-FITC, and ELISA kits including tumor necrosis factor- $\alpha$ (TNF- $\alpha$ ), IL-1 $\beta$, and IL-12p40 were purchased from Elabscience (Wuhan, China). Anti-MHC-I-FITC, anti-MHC-II-PE, and anti-CD11c-PE were bought from BD Biosciences (San Diego, CA, USA).

\subsection{Preparation of G. uralensis Crude Polysaccharides (GUPS-C)}

G. uralensis roots were collected from Yili in Xinjiang Uygur autonomous region, China. Polysaccharides were isolated using a previously-described procedure with some modifications [23]. In brief, $100 \mathrm{~g}$ of G. uralensis minced roots were extracted by $500 \mathrm{~mL}$ of petroleum ether twice at $60^{\circ} \mathrm{C}$ for $1 \mathrm{~h}$; then, the residues were collected and extracted with $500 \mathrm{~mL}$ of $80 \%$ ethanol twice at $60{ }^{\circ} \mathrm{C}$ for $1 \mathrm{~h}$. The residues was collected and dissolved in $800 \mathrm{~mL}$ of distilled water. After treatment with ultrasonication for $20 \mathrm{~min}$, the solution was placed in water bath at $60^{\circ} \mathrm{C}$ for $2 \mathrm{~h}$. The step was repeated once. The supernatant was collected and concentrated using a rotary vacuum evaporator at $40{ }^{\circ} \mathrm{C}$, then decolored with $5 \%$ active carbon for $30 \mathrm{~min}$. The concentrated solution was precipitated twice with 4 volumes of ethanol at $4{ }^{\circ} \mathrm{C}$ for $24 \mathrm{~h}$. After spinning down at $9610 \mathrm{~g}$ for $15 \mathrm{~min}$, the GUPS-C was obtained. 


\subsection{Purification of GUPS}

GUPS-C was further purified by DEAE-52 chromatography according to our previous protocol with a minor modification [11]. In brief, $0.5 \mathrm{~g}$ of GUPS-C was dissolved in $200 \mathrm{~mL}$ distilled water and filtered through $0.22 \mu \mathrm{M}$ filter. The solution was concentrated to $50 \mathrm{~mL}$, and applied to a column $(2.6 \mathrm{~cm} \times 20 \mathrm{~cm})$ of DEAE-52 cellulose equilibrated with water. One column volume $(\mathrm{CV})$ is about $106.186\left(\mathrm{~cm}^{3}\right)$. After loading with the sample, the column was step-wise eluted with $3 \mathrm{CV}$ of distilled water and gradients of $\mathrm{NaCl}$ solutions $(0.1,0.2,0.5$, and $1 \mathrm{M})$ at a flow rate of $1 \mathrm{~mL} / \mathrm{min}$. The fractions were collected at 7 min intervals with a fraction collector (ÄKTA Purifier 100, GE, Marlborough, MA, USA) and measured by the phenol-sulfuric acid method. Three major peaks were obtained according to the elution with water, $0.1 \mathrm{M}$, and $0.2 \mathrm{M} \mathrm{NaCl}$ solutions, respectively. The major fractions of each peak were pooled, dialyzed, and freeze-dried to yield the polysaccharide powder, named GUPS-I, GUPS-II, and GUPS-III, respectively. Their yields were 30\%, $8 \%$, and $16 \%$, respectively.

\subsection{Analysis of Carbohydrate, Protein, and Sulfate Contents}

Total carbohydrate was determined by the phenol-sulfuric acid method using glucose as the standard [24]. Protein was determined by using BCA Protein Assay Kit (Thermo, Waltham, MA, USA) according to the manufacturer's instruction. The sulfate contents were determined by $\mathrm{BaCl}_{2}$-gelatin assay using potassium sulfate as the standard [25]. Polysaccharide solutions of $1 \mathrm{mg} / \mathrm{mL}$ concentration were scanned from $200 \mathrm{~nm}$ to $400 \mathrm{~nm}$ with a UV spectrophotometer (UV-3600).

\subsection{Monosaccharide Composition Analysis}

The monosaccharide composition of GUPS was analyzed by GC-MS [26]. GlcA, Glc, Gla, Man, Ara, Rha, and Xyl were used as the monosaccharide standards. Briefly, $10 \mathrm{mg}$ of GUPS was hydrolyzed with $4 \mathrm{~mL}$ of $2 \mathrm{M}$ TFA at $110{ }^{\circ} \mathrm{C}$ for $6 \mathrm{~h}$ under a $\mathrm{N}_{2}$ atmosphere. The monosaccharides and hydrolyzed products were reacted with $10 \mathrm{mg}$ of $\mathrm{NaBH}_{4}$, pyridine $(0.5 \mathrm{~mL})$, and acetic anhydride $(0.5 \mathrm{~mL})$ at $90^{\circ} \mathrm{C}$ for $30 \mathrm{~min}$ to prepare the acetylated samples, which were detected by GC-MS with an OV-1701 capillary column $(30 \mathrm{~m} \times 0.32 \mathrm{~mm})$. The temperature program was set at $160^{\circ} \mathrm{C}$ and then gradually increased to $230^{\circ} \mathrm{C}$ at an increment of $5{ }^{\circ} \mathrm{C} / \mathrm{min}$, with the carrier gas of high purity $\mathrm{He}_{2}$ and flame ionization detector being set at $270^{\circ} \mathrm{C}$. The injection volume was $1 \mu \mathrm{L}$.

\subsection{Molecular Weight Determination}

The homogeneity and molecular weight of GUPS were determined by HPGPC according to our previous study [11]. A set of dextran standards with molecular weights of 10, 40, 70, 500, and $2000 \mathrm{kDa}$ were used to make the standard curve. The molecular weight of GUPS was estimated according to the standard curve.

\subsection{SEM Analysis}

For the morphologies of GUPS, the samples were coated with a thin gold layer and observed by scanning electronic microscope (SU8010, Hitachi, Tokyo, Japan).

\subsection{Fourier Transform Infrared (FT-IR) Spectroscopy and Nuclear Magnetic Resonance (NMR) Spectroscopy}

First, $5 \mathrm{mg}$ of GUPS was mixed with $400 \mathrm{mg}$ of $\mathrm{KBr}$ to make a tablet and recorded on an FT-IR spectrometer (Bruker, VERTEX 70, Fallanden, Switzerland) from 4000 to $400 \mathrm{~cm}^{-1}$ with 64 scans at $4 \mathrm{~cm}^{-1}$ resolution using the OPUS 6.5 software (Bruker).

Approximately $40 \mathrm{mg}$ of GUPS was dissolved in $0.5 \mathrm{~mL}$ of $\mathrm{D}_{2} \mathrm{O}$ and then analyzed using a Bruker $600 \mathrm{MHz}$ NMR apparatus (Bruker, Fallanden, Switzerland) at $60^{\circ} \mathrm{C}$. The one-dimensional spectra $\left({ }^{1} \mathrm{H}\right.$ and ${ }^{13} \mathrm{C}$ ) and two-dimensional spectra (HSQC and HMBC) were measured. Chemical shifts of GUPS were expressed in ppm. 


\subsection{DPPH Radical Scavenging Assay}

The DPPH radical scavenging assay was performed according to previous description [27]. Briefly, $50 \mu \mathrm{L}$ of GUPS fractions at different concentrations $(0.05,1,2,3,4$, and $5 \mathrm{mg} / \mathrm{mL})$ were mixed with $150 \mu \mathrm{L}$ of $0.2 \mathrm{mM}$ DPPH ethanol solution. The ascorbic acid $(\mathrm{Vc})$ was used as positive control. The OD was measured at $517 \mathrm{~nm}$ using a microplate reader (Bio-Rad, Hercules, CA, USA). The DPPH radical scavenging capability was calculated according to the equation:

$$
\text { Scavenging rate }(\%)=[(\mathrm{Ab}-\mathrm{As}) / \mathrm{Ab}] \times 100 \%
$$

$\mathrm{Ab}$ is the OD in the absence of the test sample and $\mathrm{As}$ is the OD in the presence of the test sample.

\subsection{Generation and Treatment of Bone Marrow-Derived DCs}

Dendritic cells were generated from bone marrow cells of C57BL/6 mice in the presence of GM-CSF following a previously-described protocol [28]. On day 7, DCs were harvested and treated with different concentrations $(10,50 \mu \mathrm{g} / \mathrm{mL})$ of GUPS for $12 \mathrm{~h}$. LPS $(20 \mathrm{ng} / \mathrm{mL})$ were used as the positive control.

For the analysis of phagocytosis of DCs, cells were incubated with FITC-Dextran (Sigma-Aldrich) for $1 \mathrm{~h}$ after treatment with GUPS ( $50 \mu \mathrm{g} / \mathrm{mL}$ ) or LPS for $12 \mathrm{~h}$ and analyzed by a flow cytometer.

\subsection{Animal Experiment}

C57BL/6 mice (6-8 weeks of age) were bought from Animal Laboratory Center, Xinjiang Medical University (Urumqi, Xinjiang, China) and housed in a temperature-controlled, light-cycled animal facility in Xinjiang University. Mice (3 mice/group) were injected with GUPS-I, GUPS-II, or GUPS-III (100 $\mu \mathrm{g} / \mathrm{mice})$ or LPS (100 ng/mouse) by both sides of footpads ( $25 \mu \mathrm{L} /$ footpad). Mice injected with PBS or LPS were used as negative or positive controls. After $24 \mathrm{~h}$, popliteal lymph nodes (LNs) were isolated to analyze DC maturation by using a flow cytometer.

\subsection{Ethics Statements}

All animal experiments were approved by the Committee on the Ethics of Animal Experiments of Xinjiang Key Laboratory of Biological Resources and Genetic Engineering (BRGE-AE001) and carried out under the guidelines of the Animal Care and Use Committee of College of Life Science and Technology, Xinjiang University.

\subsection{Flow Cytometry}

For in vitro analysis of DC maturation, GUPS treated cells were stained with fluorescence-conjugated anti-CD11C, anti-CD40, anti-CD86, and anti-MHC-I/II at room temperature (RT) for $15 \mathrm{~min}$. For the detection of the phagocytosis activity of DCs, cells were stained with anti-CD11c-PE at RT for $15 \mathrm{~min}$ and collected by FACSCalibur. For in vivo analysis of DC maturation, the lymphocytes of popliteal LNs were stained with fluorescence-conjugated anti-CD11c, anti-CD40, anti-CD86, and anti-MHC-I/II at RT for $15 \mathrm{~min}$. All samples were collected by FACSCalibur (BD Biosciences) and the data were analyzed using FlowJo software (Tree Star, Inc., Ashland, OR, USA).

\subsection{ELISA Assay of Cytokines}

The supernatants of DC culture were collected and the levels of TNF- $\alpha$, IL-1 $\beta$, and IL-12p40 were determined by ELISA kits according to the manufacturer's instruction. 


\subsection{Data Analysis}

All experiments were carried out at least thrice, and the data were expressed as mean \pm SD. Statistical analysis was carried out by one-way analysis of variance (ANOVA) using Prism5.0 software. $p<0.05$ was considered to be statistically significant.

\section{Results}

\subsection{Purification and Physicochemical Characterization of GUPS}

The crude polysaccharides of G. uralensis (GUPS-C) were isolated using the method of hot water extraction and alcohol deposition according to the procedure in Figure 1. The yield of GUPS-C was approximately $2.73 \%(w / w)$. GUPS-C was further separated through cellulose DEAE-52 anion-exchange column with elution by different concentrations of $\mathrm{NaCl}$. As shown in Figure 1, three fractions, i.e., GUPS-I, GUPS-II, and GUPS-III, were collected, concentrated, dialyzed, and lyophilized. GUPS-I eluted with distilled water might be a neutral polysaccharide, whereas both GUPS-II and GUPS-III eluted with $\mathrm{NaCl}$ solution might be acidic polysaccharides [29].
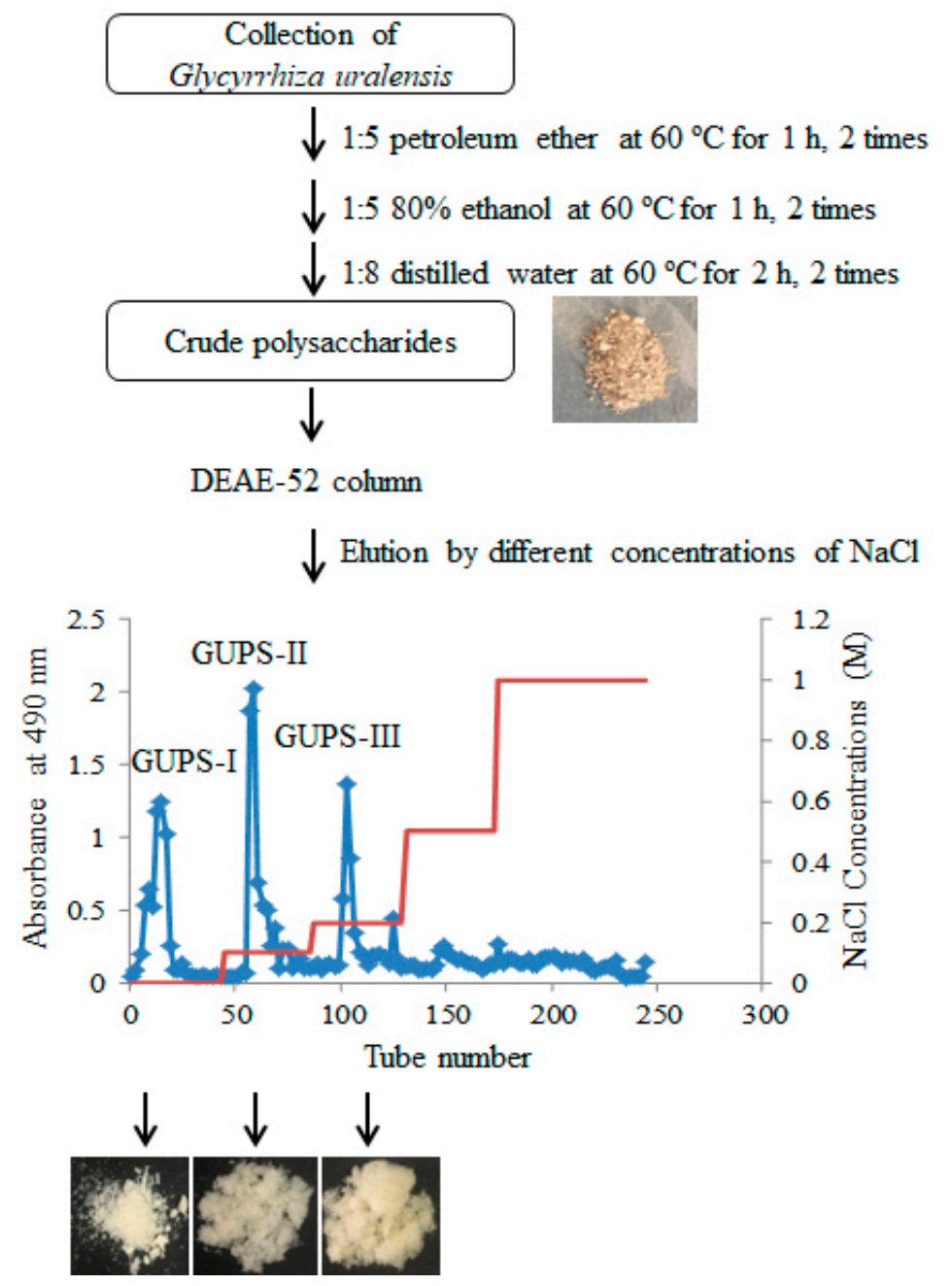

Figure 1. The strategy of GUPS purification.

The physicochemical properties of the GUPS were determined and shown in Table 1. GUPS-I is white and granulated, while GUPS-II and -III are yellow and loose. The molecular weights of GUPS-I, -II, and -III are 1060, 29,100, and 14,900 Da, respectively. The total carbohydrate contents of GUPS-C, GUPS-I, GUPS-II, and GUPS-III were 37\%, 29\%, 93\%, and 75\%, respectively. Based on the BCA test, 
GUPS-I and GUPS-II did not contain protein, but GUPS-C and GUPS-III contained 4\% and 21.5\% protein, respectively. This is consistent with the result from the UV-Visible spectroscopy of the three fractions (Supplementary Figure S1). The sulfate contents of GUPS-I, GUPS-II, and GUPS-III were $6.5 \%, 8.7 \%$, and $20.47 \%$ respectively.

Table 1. Physicochemical properties of GUPS.

\begin{tabular}{ccccc}
\hline Samples & GUPS-C & GUPS-I & GUPS-II & GUPS-III \\
\hline Color & Brown & White & Faint yellow & Yellow \\
Texture & Granulate & Granulate & Loose & Loose \\
Water solubility & Better & Good & Good & Good \\
Molecular Weight $(\mathrm{Da})$ & $\mathrm{nm}$ & 1060 & 29100 & 14900 \\
Carbohydrate content $(\%)$ & $37.7 \pm 0.34$ & $29.1 \pm 0.14$ & $93.5 \pm 0.68$ & $75.2 \pm 0.54$ \\
Protein content $(\%)$ & $4.1 \pm 0.04$ & 0 & 0 & $21.5 \pm 0.02$ \\
Sulfate content $(\%)$ & $\mathrm{nm}$ & $6.5 \pm 0.45$ & $8.7 \pm 0.23$ & $20.5 \pm 0.76$ \\
\hline
\end{tabular}

\subsection{Monosaccharide Composition of GUPS}

The monosaccharide composition of GUPS-I, GUPS-II, and GUPS-III was analyzed by GC-MS and compared with monosaccharide standards. The results showed that GUPS-I was composed of Rha, Xyl, and Glc at molar ratios of 2.55:1.9:30.03, GUPS-II consisted of Rha, Ara, Man, Glc, and Gal at molar ratios of 1:13.87:1.59:16.76:15.72, and GUPS-III was composed of Ara, Man, Glc, and Gal at molar ratios of 1:5.33:1.91:5.97 (Figure 2). The monosaccharide composition of GUPS-II was similar to that determined in previous studies, but GUPS-III had some differences, such as the mannose content [30,31].

\subsection{Scanning Electron Microscopy (SEM) Analysis of GUPS}

The preliminary structures of GUPS-I, GUPS-II, and GUPS-III were observed using SEM at 2000- and 10,000-fold magnifications (Figure 3). GUPS-I was granulated, suggesting that it is mainly composed of the oligosaccharide. This is consistent with its low molecule weight. However, GUPS-II and GUPS-III were flaky without a porous structure. Furthermore, GUPS-II and GUPS-III showed a smooth surface at 10,000-fold magnification, suggesting that they may form an amorphous structure.

\subsection{The Analysis of GUPS by FT-IR Spectroscopy}

FT-IR spectra of carbohydrates are commonly used for the determination of structural features [32]. As shown in Figure 4, the IR spectra of GUPS-I, GUPS-II, and GUPS-III had a broad, intense hydroxyl group stretching band at 3400-3300 $\mathrm{cm}^{-1}$ and a weak C-H stretching band at around $3000-2800 \mathrm{~cm}^{-1}$, which are the characteristics of polysaccharides [12,33]. In the three spectra, the absorption peaks at approximately $1610-1655 \mathrm{~cm}^{-1}$ corresponded to carbonyl groups $(\mathrm{C}=\mathrm{O})$ and were caused by the bending mode of bound water, while the absorption peak at approximately $1400 \mathrm{~cm}^{-1}$ was the C-O stretching vibration $[26,29,34,35]$. A strong absorption peak at $1615 \mathrm{~cm}^{-1}$ presented carboxyl groups (COO-) in GUPS-III, indicating the existence of uronic acids [36,37]. A strong band between 950 and $1160 \mathrm{~cm}^{-1}$ in the three spectra of GUPS were attributed to the stretching vibrations of the pyranose ring [38]. In addition, the peak appeared at approximately $1077 \mathrm{~cm}^{-1}$ in the three spectra was the result of the glycosidic linkage stretch vibration of $\mathrm{C}-\mathrm{O}-\mathrm{C}$ bond [34]. The characteristic absorption peaks at 890-920 $\mathrm{cm}^{-1}$ in GUPS-II and GUPS-III were due to $\beta$-pyranose configuration [5]. Moreover, a weak band at approximately $860 \mathrm{~cm}^{-1}$ in GUPS-II was attributed to $\alpha$-glycosidic linkages in the polysaccharide chains. Another weak band at $1250-1244 \mathrm{~cm}^{-1}$ in GUPS-III was regarded as the $\mathrm{S}=\mathrm{O}$ vibration, suggesting that GUPS-III may consist of sulfated polysaccharides [39-41]. This is in consistent with the sulfate content of GUPS-III. 
A

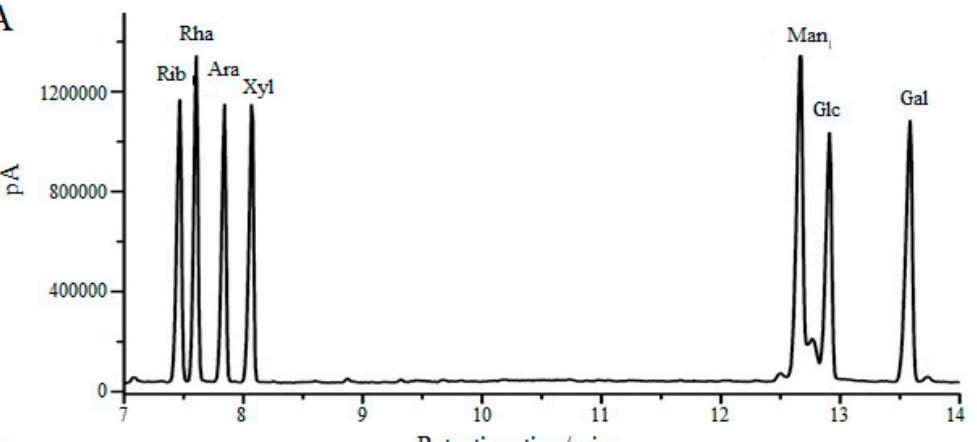

B
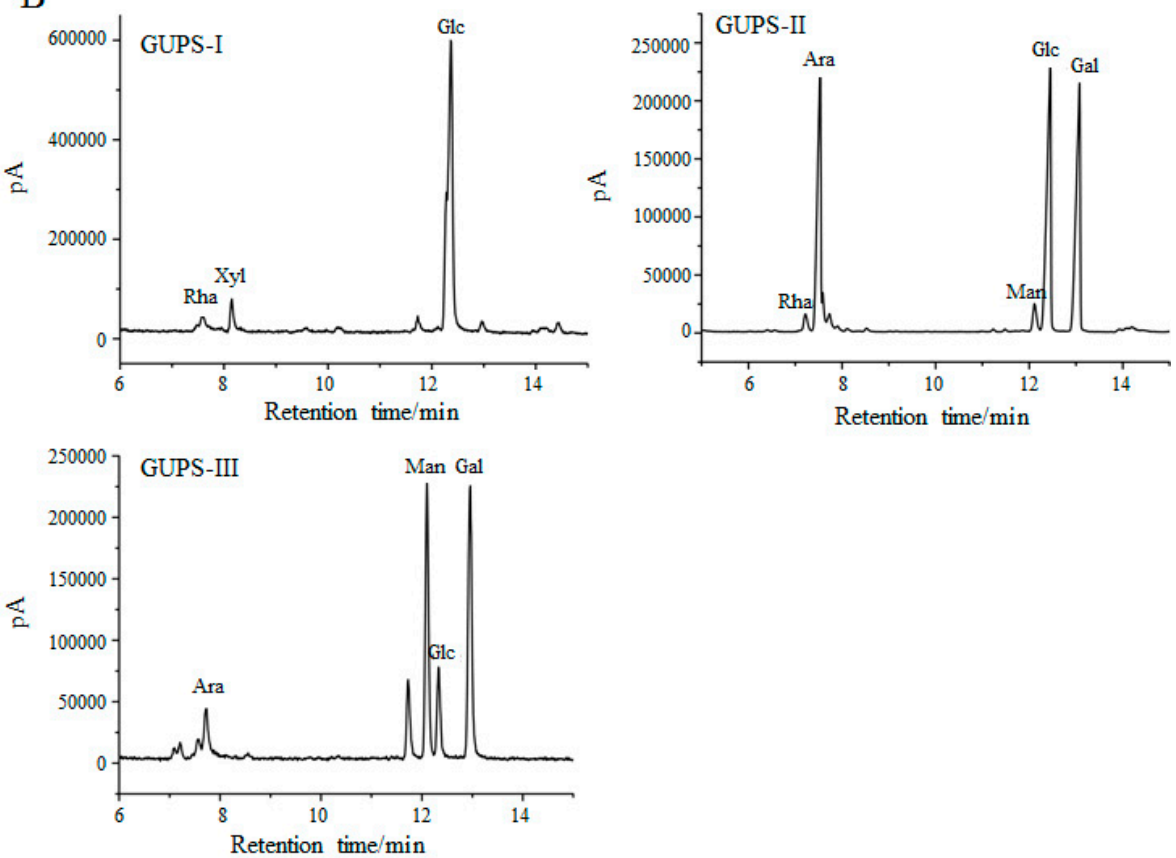

Figure 2. The monosaccharide composition of GUPS. (A) The GC-MS of standard monosaccharides. (B) The GC-MS of GUPS-I, GUPS-II, and GUPS-III.

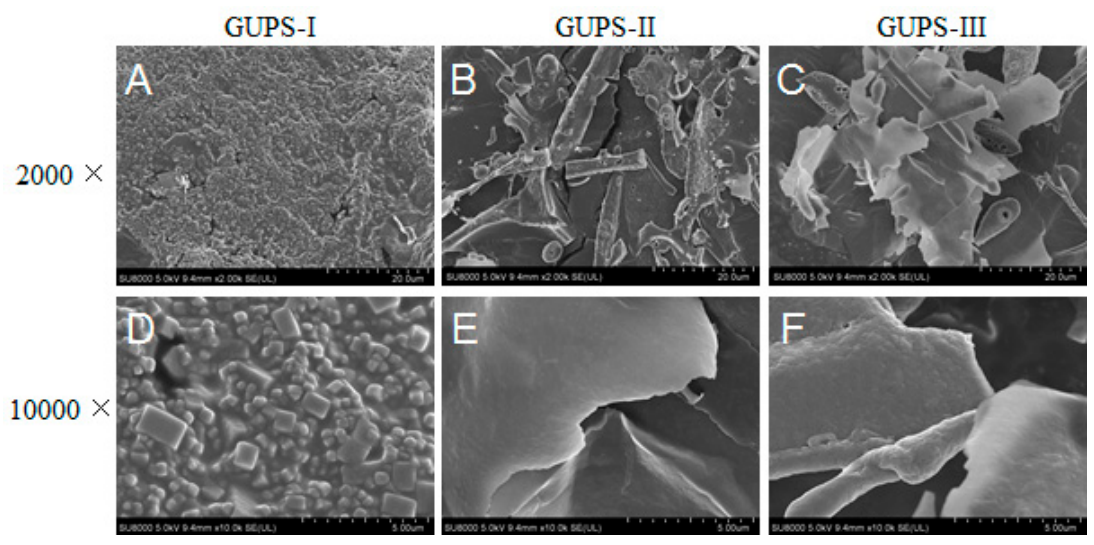

Figure 3. SEM images of GUPS-I, GUPS-II and GUPS-III. The magnifications of (A-C) and (D-F) are $2000 \times$ and $10,000 \times$. 

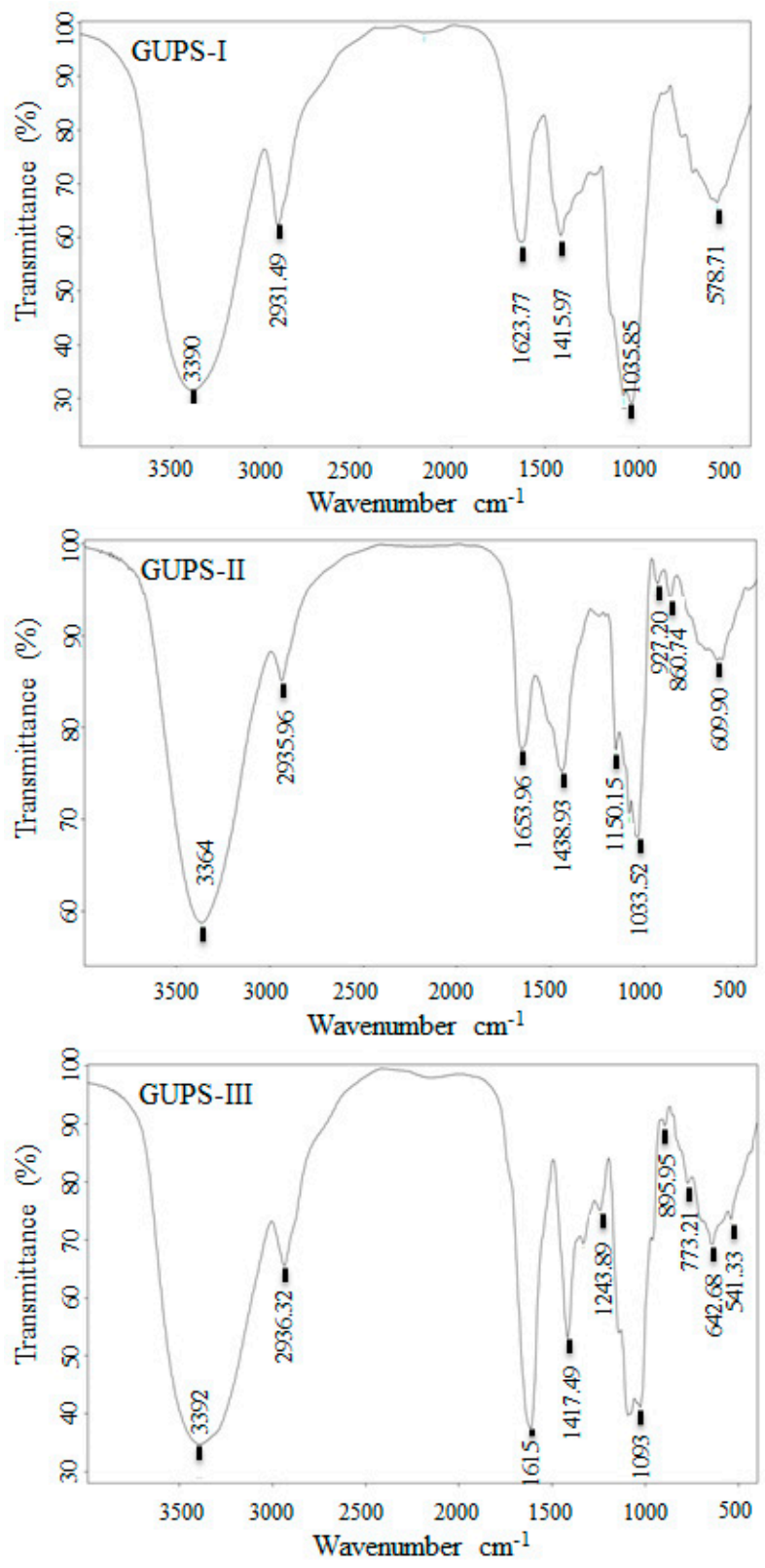

Figure 4. FT-IR spectra of GUPS-I, GUPS-II, and GUPS-III.

\subsection{The NMR Spectrum of GUPS}

NMR spectroscopy is an efficient way to elucidate the chemical constituents of polysaccharides [42]. GUPS-I, GUPS-II and GUPS-III were analyzed via ${ }^{1} \mathrm{H}$ NMR, ${ }^{13} \mathrm{C}$ NMR, HSQC, and HMBC. As shown in Figure 5, the ${ }^{1} \mathrm{H}$ and ${ }^{13} \mathrm{C}$ NMR spectra of these three GUPSs were crowded in a narrow region within 3.0-5.3 ppm ( ${ }^{1} \mathrm{H}$ NMR $)$ and $60-110 \mathrm{ppm}\left({ }^{13} \mathrm{C}\right.$ NMR $)$, which are typical characteristics of polysaccharides $[43,44]$. Anomeric proton signals at $\delta 5.09,5.23$, and $5.39 \mathrm{ppm}$, and anomeric carbon signals at $\delta 99.69,95.2$, and 92.24 ppm were observed in GUPS-I (Figure 5A,B), which revealed that it might be composed of three types of monosaccharide residues, and only contained $\alpha$-glycosidic linkage. This is consistent with its monosaccharide composition. According to the ${ }^{1} \mathrm{H}^{13} \mathrm{C}$ HSQC (Figure 6A) and HMBC (Figure 6B) spectra, the signals were very weak, indicating that the structure of GUPS-I was relatively simple. However, the ${ }^{1} \mathrm{H}$ NMR and ${ }^{13} \mathrm{C}$ NMR spectra of the GUPS-II and GUPS-III revealed that they contained both $\beta$-glycosidical and $\alpha$-glycosidical configurations (Figure $5 \mathrm{C}-\mathrm{F}$ ). The ${ }^{1} \mathrm{H}$ NMR spectrum of GUPS-II contains nine main anomeric proton signals at $\delta 5.28,5.26,5.13$, $5.06,5.03,4.97,4.854 .53$, and 4.52 ppm, while GUPS-III contained six main anomeric proton signals at 
$\delta 5.66,5.58,5.13,5.03,4.97$, and $4.36 \mathrm{ppm}$. The proton signals at $\delta 5.28$ in GUPS-II and $\delta 5.58 \mathrm{ppm}$ in GUPS-III indicated the presence of $\alpha$-L-Ara. The proton signal at $\delta 5.26 \mathrm{ppm}$ indicated the presence of $\alpha$-L-Rhap in GUPS-II but not in GUPS-III. This was consistent with their monosaccharide composition (Figure 3). But the signals at $\delta 1.12-1.19 \mathrm{ppm}$ in GUPS-III indicated the presence of methyl group of Rha. Weak signals at around $\delta 2.0$ ppm (2.02 and $1.99 \mathrm{ppm})$ in GUPS-III were associated with acetyl groups binding at O-2 and O-3 of GalpA, respectively. Signals at approximately $\delta 175$ ppm in ${ }^{13} \mathrm{C}$ NMR spectrum from GUPS-III further proved that the $\alpha$-D-GalpA was partly methyl esterified. This is in accordance with the FT-IR spectrum of GUPS-III, which contained a strong absorption at $1615 \mathrm{~cm}^{-1}$. According to HSQC spectra (Figure 6C,E), the anomeric proton and carbon signals were analyzed as follows. Signals at $\delta$ 4.98/107.43, 4.92/107.32, 5.21/99.82, 5.29/99.63, and 4.51/95.62 in GUPS-II were assigned to the H-1/C-1 of $\alpha$-L-Ara $f-(1-, 3)-\alpha$-L-Rha- $(1-, 3)-\alpha-D-G a l p-(1-, \alpha-D-X y l p-(1-$, and $-4)-\alpha-D-G l c p-(1-$ residues, respectively. Signals at $\delta 4.98 / 107.37,4.96 / 107.31$ in GUPS-III were assigned to the H-1/C-1 of $\alpha$-L-Araf-(1-, 3)- $\alpha$-L-Rha-(1- residues, respectively. The HMBC was used to determine the sequence of these residues in the repeating unit and to verify the assignments from HSQC [45]. The HMBC spectrum of GUPS-II was different to that of GUPS-III, suggesting that GUPS-II and GUPS-III have different structural characteristics (Figure 6D,F).
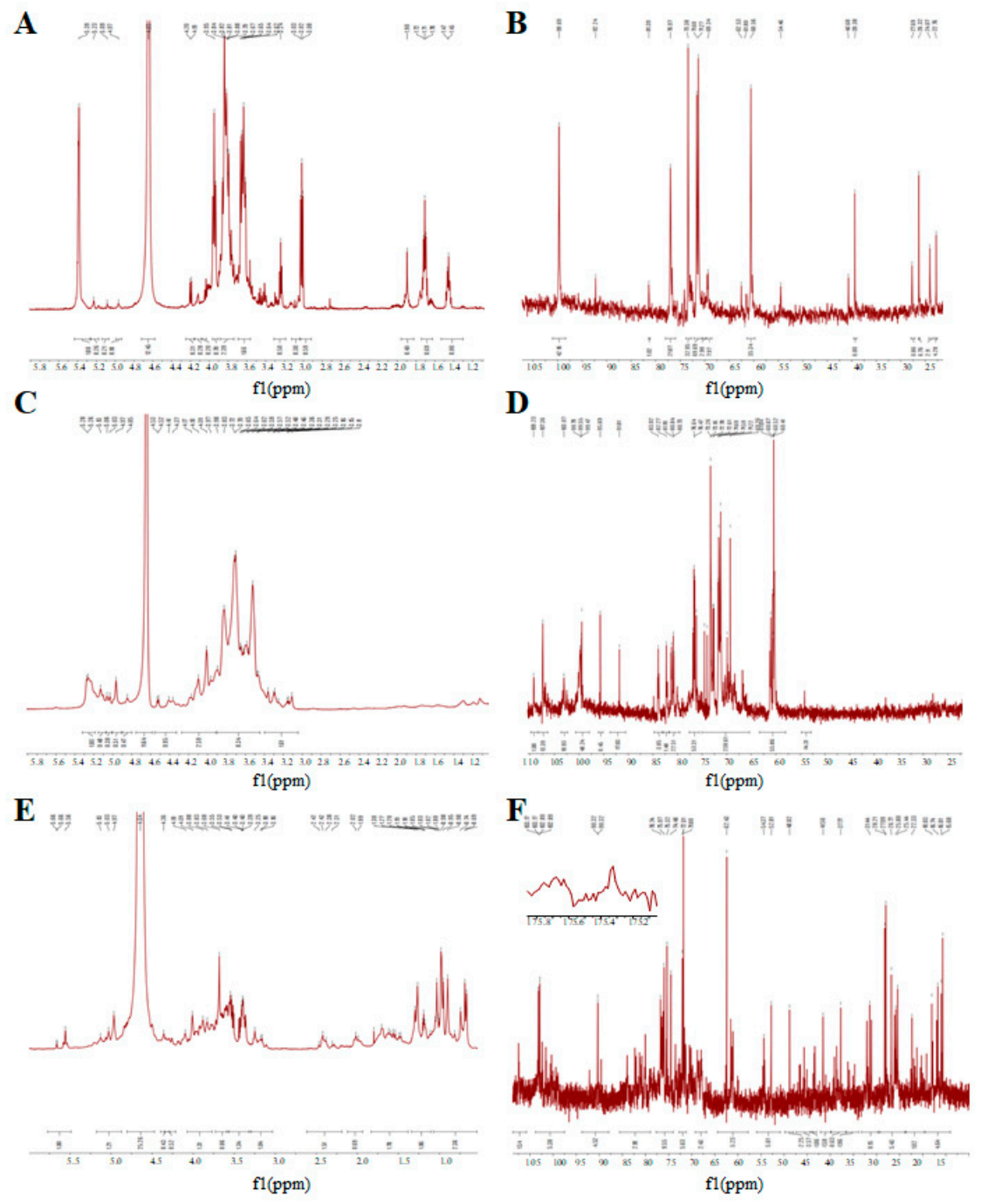

Figure 5. One-dimensional NMR spectra of GUPS. (A) ${ }^{1} \mathrm{H}$ NMR spectrum of GUPS-I; (B) ${ }^{13} \mathrm{C}$ NMR spectrum of GUPS-I; (C) ${ }^{1} \mathrm{H}$ NMR spectrum of GUPS-II; (D) ${ }^{13} \mathrm{C}$ NMR spectrum of GUPS-II; (E) ${ }^{1} \mathrm{H}$ NMR spectrum of GUPS-III; (F) ${ }^{13}$ C NMR spectrum of GUPS-III. 
A

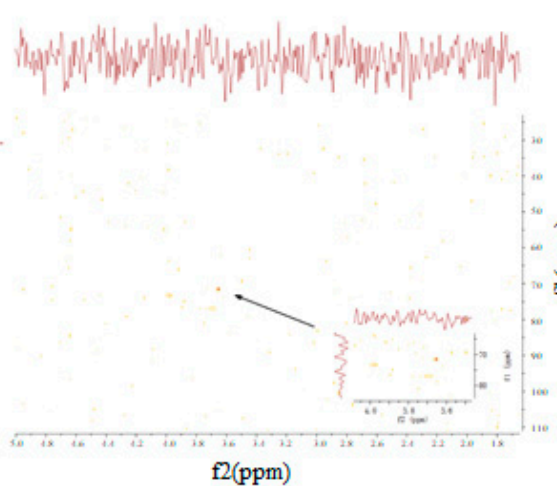

C

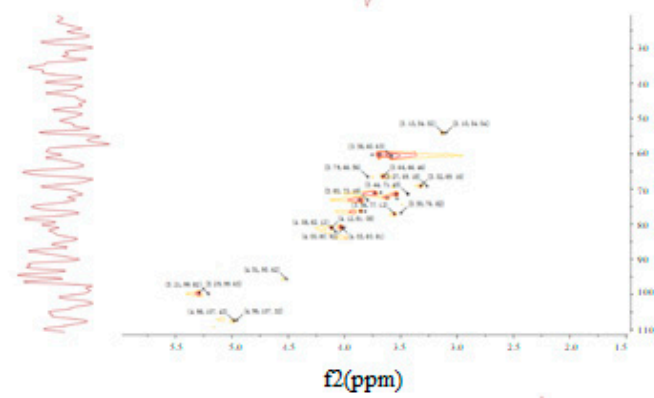

$\mathbf{E}$

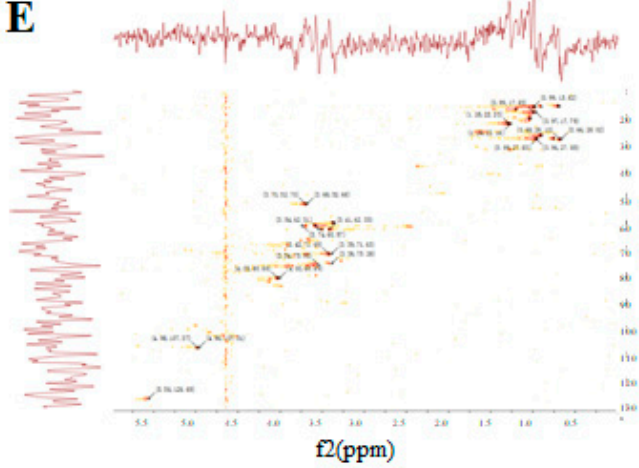

B
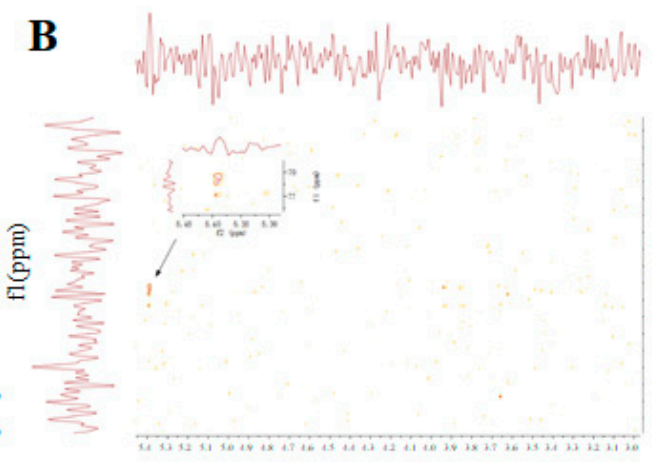

D
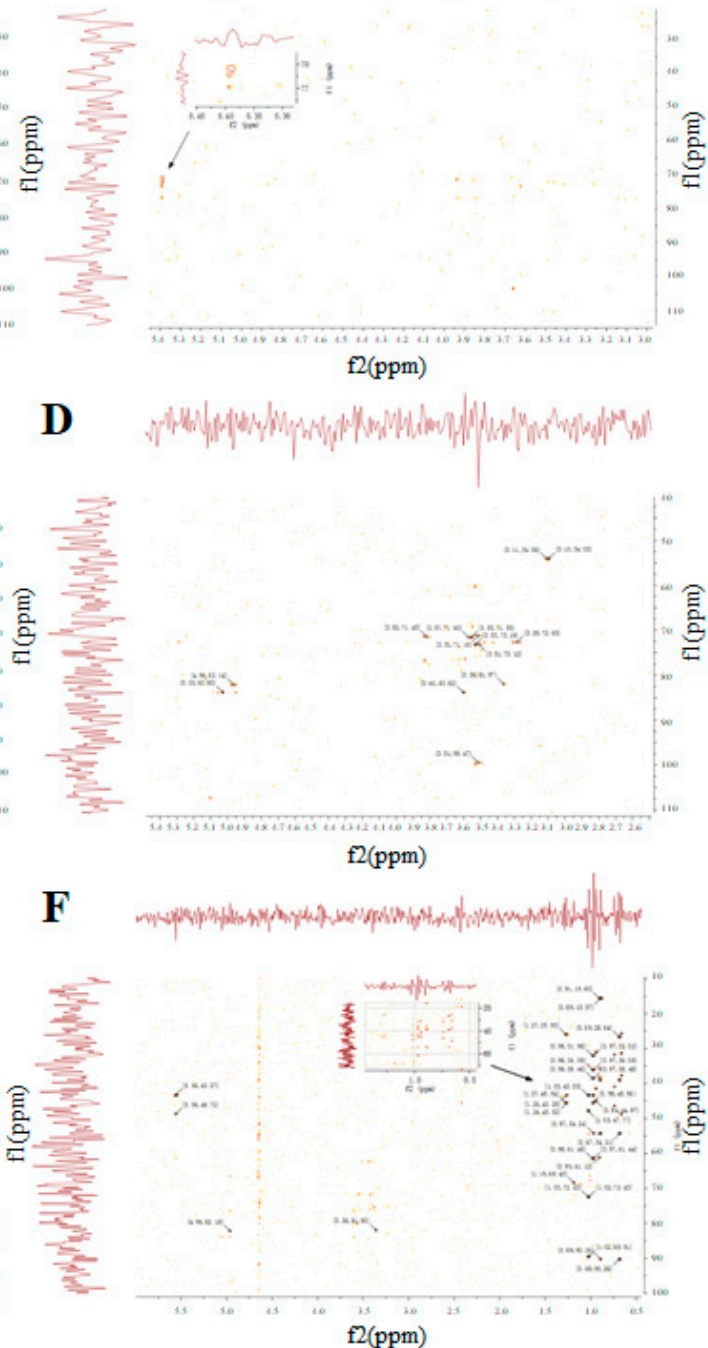

f2(ppm)
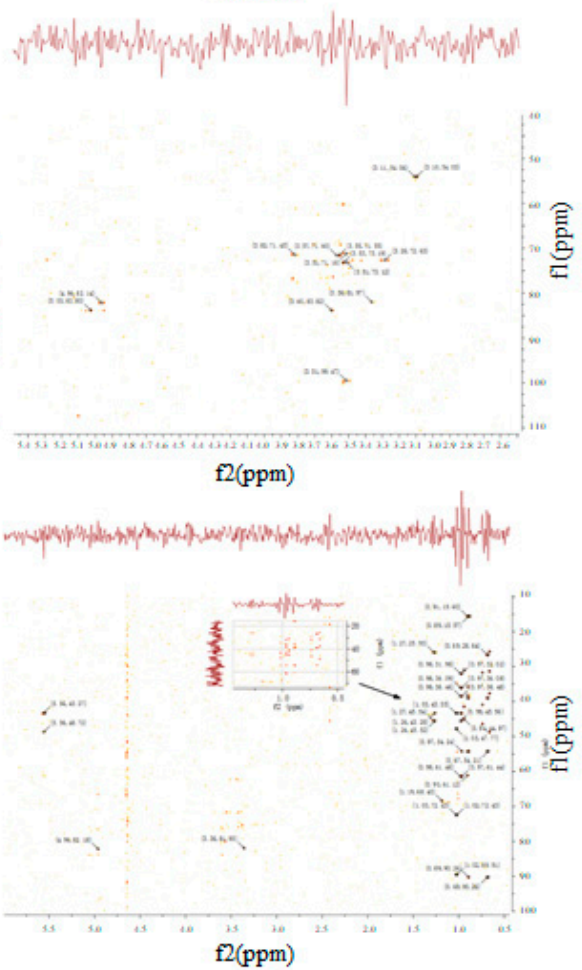

Figure 6. Two-dimensional NMR spectra of GUPS. (A) HSQC spectrum of GUPS-I; (B) HMBC spectrum of GUPS-I; (C) HSQC spectrum of GUPS-II; (D) HMBC spectrum of GUPS-II; (E) HSQC spectrum of GUPS-III; (F) HMBC spectrum of GUPS-III.

\subsection{GUPS Promotes the Maturation of DCs}

DCs are professional antigen-presenting cells with the ability to initiate immune responses. Recently, lots of effort has been focused on the immunomodulatory activities of natural polysaccharides, especially in DC maturation and function [10]. With the maturation of DCs, the phagocytosis activity was decreased. To evaluate the effect of GUPS on the phagocytosis of DCs, the cells were incubated with FITC-dextran after GUPS treatment and analyzed by flow cytometer. Compared with untreated DCs, the frequencies of Dextran ${ }^{+}$DCs were significantly reduced by the treatment of LPS, GUPS-I, GUPS-II, and GUPS-III (Supplementary Figure S2), indicating that the three fractions of GUPS promoted DC maturation.

We further investigated the phenotype maturation and cytokine production of DCs both in vitro and in vivo after the treatment of GUPS-I, GUPS-II, and GUPS-III. GUPS-I, GUPS-II, and GUPS-III significantly enhanced the expression of MHC-I, CD40, and CD86 (Figure 7A). All three fractions significantly increased the secretion of IL-1 $\beta$, IL-12p 40 , and TNF- $\alpha$. GUPS-II and GUPS-III showed stronger activity than GUPS-I in the cytokine production (Figure 7B). Moreover, the in vivo experiment showed that only GUPS-II significantly increased the frequencies of $\mathrm{CD} 11 \mathrm{c}^{+} \mathrm{CD} 40^{+}, \mathrm{CD} 11 \mathrm{c}^{+} \mathrm{CD} 86^{+}$, 


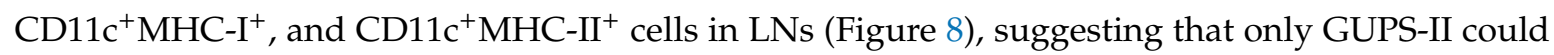
promote DC maturation in vivo. The results suggested that GUPS-II has stronger immuno-enhancing activity than GUPS-I and GUPS-III, which might be due to the high molecule weight and polysaccharide content of GUPS-II.
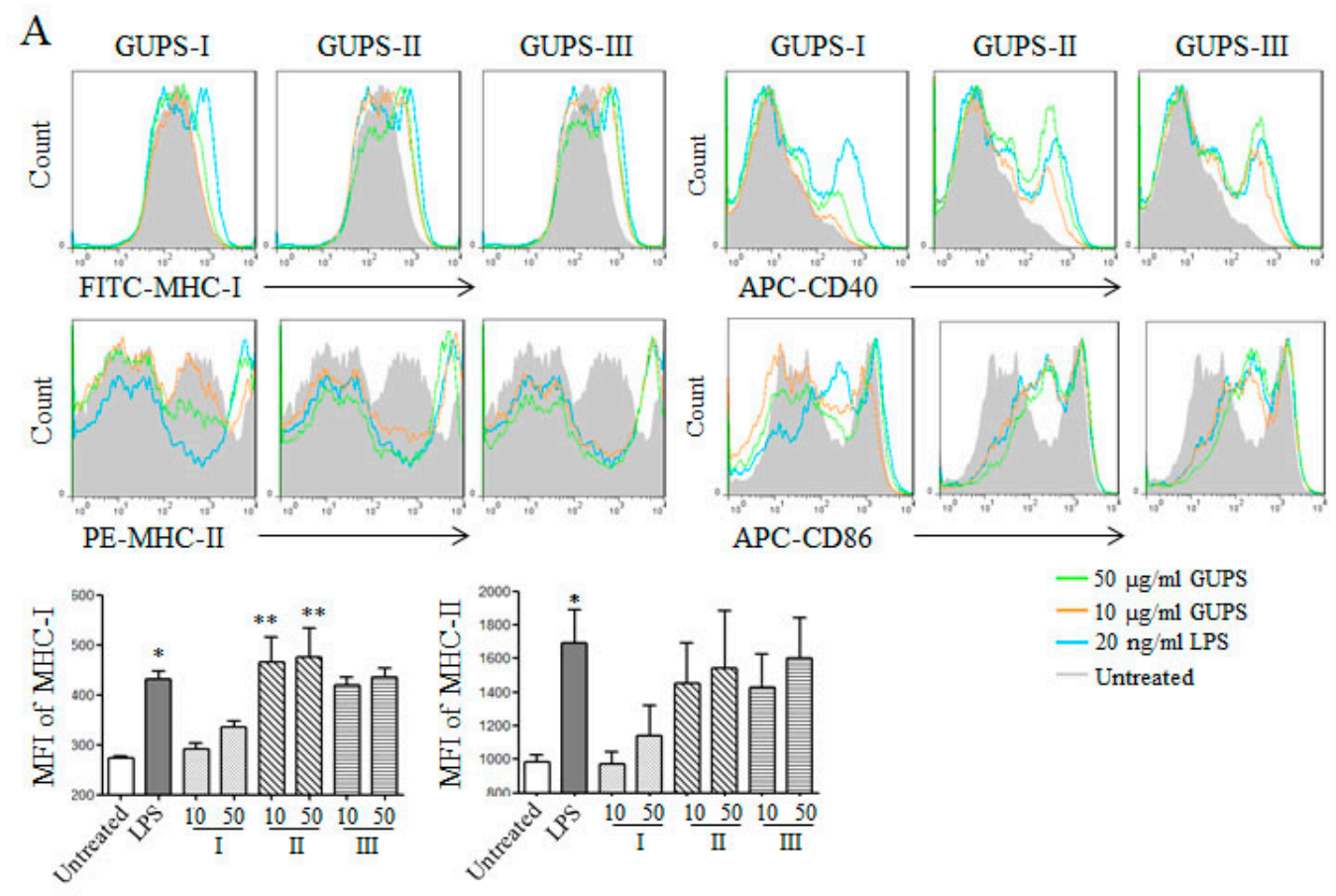

$$
\begin{aligned}
& -50 \mu \mathrm{g} / \mathrm{ml} \text { GUPS } \\
& -10 \mu \mathrm{g} / \mathrm{ml} \text { GUPS } \\
& -20 \mathrm{ng} / \mathrm{ml} \text { LPS } \\
& - \text { Untreated }
\end{aligned}
$$
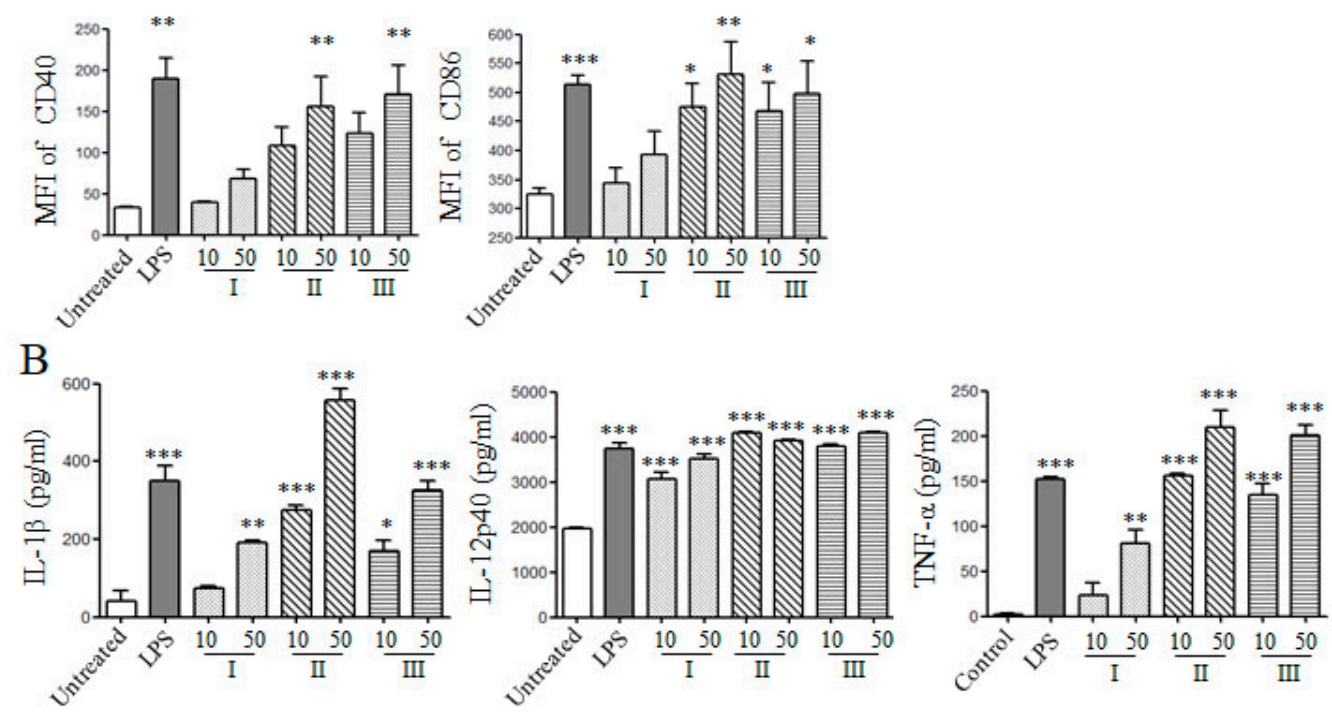

Figure 7. The effects of GUPS fractions on the maturation and cytokine production of DC in vitro. On day 7, bone marrow-derived DCs were treated with different concentrations (10 and $50 \mu \mathrm{g} / \mathrm{mL})$ of GUPS for $12 \mathrm{~h}$. (A) After treatment, the expressions of CD40, CD86, MHC I, and MHC II on DCs were detected by flow cytometry (upper panels). The mean fluorescence intensity (MFI) (mean \pm SEM) is shown in lower panels. (B) The supernatants were collected and the production of IL-1 $\beta$, IL-12p40, and TNF- $\alpha$ was detected by ELISA. The concentrations (mean \pm SEM) of cytokines are shown. Data are from three independent experiments and analyzed by ANOVA. ${ }^{*} p<0.05 ;{ }^{* *} p<0.01 ;{ }^{* * *} p<0.001$ compared with untreated DCs. 

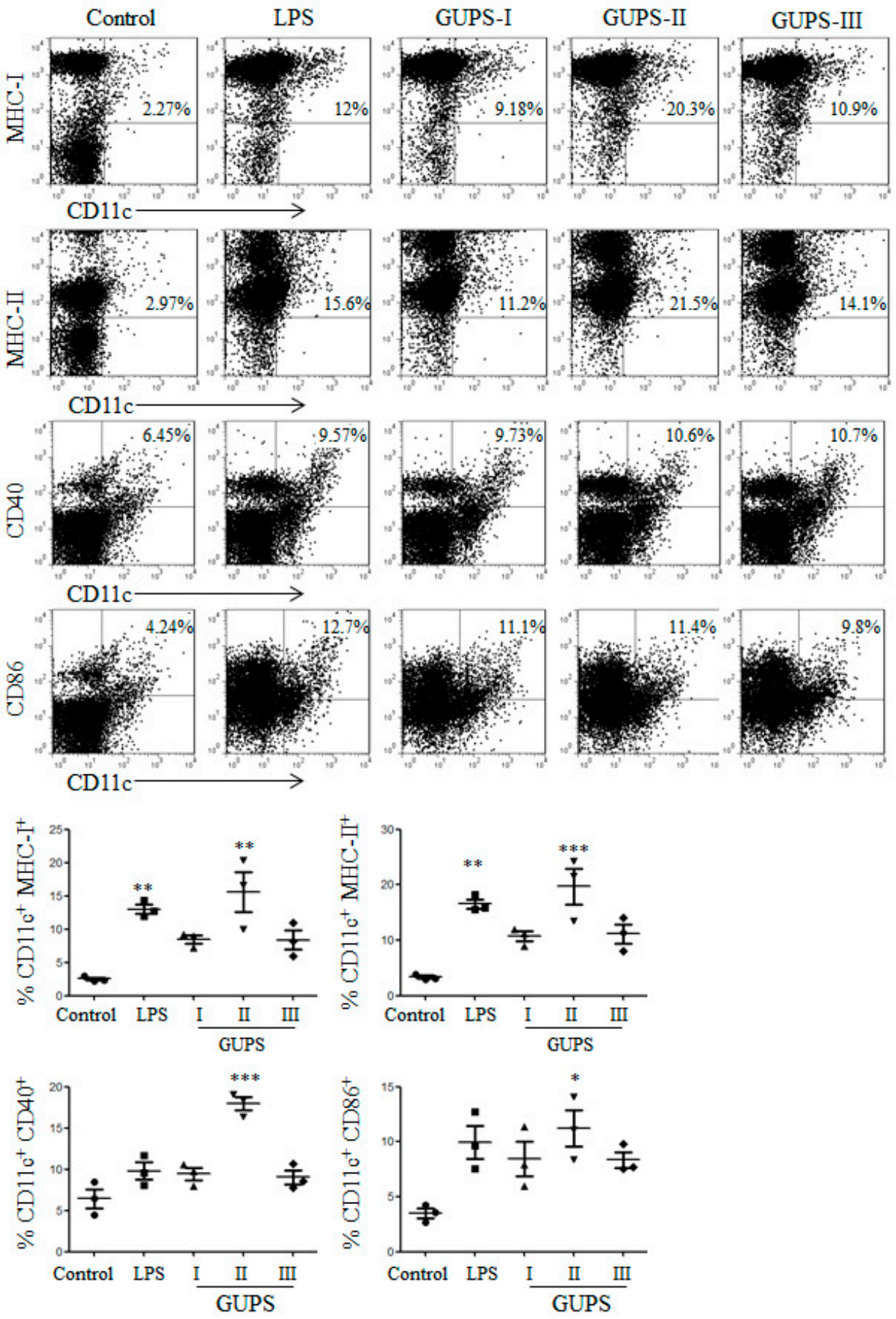

Figure 8. The effects of GUPS fractions on DC maturation in vivo. Mice were injected with GUPS-I, GUPS-II, or GUPS-III by footpads. After $24 \mathrm{~h}$, popliteal LNs were isolated to analyze DC maturation by flow cytometry (upper panels). The MFI (mean \pm SEM) is shown in lower panels. Data are analyzed by ANOVA. ${ }^{*} p<0.05 ;{ }^{* *} p<0.01 ;{ }^{* *} p<0.001$ compared with the controls.

\subsection{Diphenylpicrylhydrazyl (DPPH) Radical Scavenging Activity of GUPS}

The antioxidative activities of GUPS-I, GUPS-II, and GUPS-III were detected by DPPH radical scavenging assay. All three GUPS fractions showed the DPPH radical scavenging activities. GUPS-II and GUPS-III showed stronger antioxidative activities than that of GUPS-I (see Supplementary Figure S3). 


\section{Discussion}

Three water-soluble polysaccharides, GUPS-I, GUPS-II, and GUPS-III, with molecular weights of $1.06 \mathrm{kDa}, 29.1 \mathrm{kDa}$, and $14.9 \mathrm{kDa}$, respectively, were isolated from the herbal medicine G. uralensis via DEAE-52 ion-exchange chromatography. GUPS-I is a white granule and only contains $\alpha$-glycosidic bonds. GUPS-II and GUPS-III are flaky with a smooth surface and contain $\alpha$ - and $\beta$-glycosidic linkages. GUPS-III appears to be sulfated polysaccharides. GUPS-I might be a neutral polysaccharide because it coeluted with distilled water, whereas both GUPS-II and GUPS-III, which eluted with $\mathrm{NaCl}$ solution, might be acidic polysaccharides [29]. The results are similar to previous studies which reported that three major fractions can be obtained from crude polysaccharides of G. uralensis [30,31], but different from another study which reported that five fractions can be observed [46].

These three fractions were analyzed qualitatively using HPGPC, GC-MS, SEM, FT-IR, and ${ }^{1} \mathrm{H}-\mathrm{NMR}$. The monosaccharide composition of GUPS-II is similar to that reported in previous studies, while GUPS-III has some differences, such as its mannose content [30,31]. GUPS-I and GUPS-II do not contain any protein, whereas GUPS-C and GUPS-III contain $4 \%$ and $21.5 \%$ protein, respectively. We speculate that GUPS-C may contain some glycoproteins which may be enriched in the GUPS-III fraction. The sulfate contents of GUPS-I (6.5\%) and GUPS-II (8.7\%) are similar to those reported in previous studies, while the sulfate content of GUPS-III $(20.47 \%)$ is much higher than that in previous reports $(5.43 \%$ and $3.42 \%)[29,30]$. GUPS-II and GUPS-III are flaky without a porous structure, which is in contrast to data from a previous study [31]. GUPS-II and GUPS-III both show a smooth surface, suggesting that they may form an amorphous structure. This is also in contrast to what was reported the previous study mentioned above [31]. These results indicated that the physicochemical properties of these three GUPS fractions (extracted from G. uralensis from Xinjiang, China) are different from those polysaccharides purified by other groups from the same species but grown in different locations in previously reported studies (G. uralensis from Ningxia and from Gansu, China) [30,31]. The biotopes of G. uralensis from different places may cause the difference of polysaccharide accumulation, as well as the function of polysaccharides.

It has been reported that polysaccharides of G. uralensis have antioxidant activities $[30,31,46]$. Similarly, we also found that all three GUPS fractions have antioxidant activities. However, the antioxidant activity of GUPS-I is lower than that of GUPS-II and GUPS-III, which is different from what was reported in a previous study [30]. This may be due to the low molecular weight and carbohydrate content of GUPS-I.

Our previous study showed that GUPS-C enhances the maturation and function of DCs and the antitumor efficacy of DC-based vaccine [23]. The immuno-enhancing activities of three GUPS fractions with undetectable levels of endotoxin were further investigated using the in vitro-cultured DCs and a mouse model in the current study. We showed that GUPS-II and GUPS-III exhibit stronger activity than that of GUPS-I in the induction of DC maturation and cytokine production in vitro. Compared with GUPS-I and GUPS-III, GUPS-II showed significantly enhanced DC maturation in vivo, suggesting that it has the potential to be used along with vaccine or cancer immunotherapy as an immune-stimulator.

In conclusion, three water-soluble polysaccharides were isolated from the herbal medicine G. uralensis grown in Xinjiang. These three fractions have different physicochemical properties and different antioxidant and immuno-enhancing activities. GUPS-II has the strongest immuno-enhancing activity, which makes it a potential candidate to be developed into an immune-enhancing adjuvant for cancer immunotherapy.

Supplementary Materials: The following are available online at http://www.mdpi.com/2218-273X/10/1/159/s1, Figure S1: The UV spectra of GUPS-I, GUPS-II and GUPS-III, Figure S2: The capacity of antigen up-take of DCs upon GUPS treatment, Figure S3: The antioxidant activities of GUPS fractions.

Author Contributions: A.A. (Adila Aipire), P.Y., A.A. (Alimu Aimaier), S.C. and M.M. performed experiments. A.A. (Adila Aipire) and J.L. (Jinyao Li) analyzed data and wrote the manuscript. J.L. (Jun Lu), T.Y., B.Z. and J.L. (Jinyao Li) designed the project and revised the manuscript. All authors reviewed the manuscript. All authors have read and agreed to the published version of the manuscript. 
Funding: This work was supported by the 1000 Young Talents Program of China to Jinyao Li, the Graduate Science and Technology Innovation Project of Xinjiang University (XJUBSCX-2016016) to Adila Aipire and the New Zealand Ministry of Education, New Zealand-China Tripartite Partnership Fund to Jun Lu, Jinyao Li and Tianlei Ying.

Conflicts of Interest: The authors declare no conflict of interest.

\section{References}

1. Zhen, D.; Su, L.; Miao, Y.; Zhao, F.; Ren, G.; Mahfuz, S.; Song, H. Purification, partial characterization and inducing tumor cell apoptosis activity of a polysaccharide from Ganoderma applanatum. Int. J. Biol. Macromol. 2018, 115, 10-17. [CrossRef] [PubMed]

2. Chen, Y.; Jiang, X.; Xie, H.; Li, X.; Shi, L. Structural characterization and antitumor activity of a polysaccharide from Ramulus mori. Carbohydr. Polym. 2018, 190, 232-239. [CrossRef] [PubMed]

3. Liu, Y.; Zhang, J.; Meng, Z. Purification, characterization and anti-tumor activities of polysaccharides extracted from wild Russula griseocarnosa. Int. J. Biol. Macromol. 2018, 109, 1054-1060. [CrossRef] [PubMed]

4. Wang, Y.; Wei, X.; Wang, F.; Xu, J.; Tang, X.; Li, N. Structural characterization and antioxidant activity of polysaccharide from ginger. Int. J. Biol. Macromol. 2018, 111, 862-869. [CrossRef] [PubMed]

5. Liu, Y.; Huang, G.; Hu, J. Extraction, characterisation and antioxidant activity of polysaccharides from Chinese watermelon. Int. J. Biol. Macromol. 2018, 111, 1304-1307. [CrossRef]

6. Deng, Y.; Li, M.; Chen, L.X.; Chen, X.Q.; Lu, J.H.; Zhao, J.; Li, S.P. Chemical characterization and immunomodulatory activity of acetylated polysaccharides from Dendrobium devonianum. Carbohydr. Polym. 2018, 180, 238-245. [CrossRef]

7. Dong, Z.; Li, C.; Huang, Q.; Zhang, B.; Fu, X. Characterization of a novel polysaccharide from the leaves of Moringa oleifera and its immunostimulatory activity. J. Funct. Foods 2018, 49, 391-400. [CrossRef]

8. Lee, J.H.; Lee, Y.K.; Choi, Y.R.; Park, J.; Jung, S.K.; Chang, Y.H. The characterization, selenylation and anti-inflammatory activity of pectic polysaccharides extracted from Ulmus pumila L. Int. J. Biol. Macromol. 2018, 111, 311-318. [CrossRef]

9. Wang, M.; Zhu, P.; Zhao, S.; Nie, C.; Wang, N.; Du, X.; Zhou, Y. Characterization, antioxidant activity and immunomodulatory activity of polysaccharides from the swollen culms of Zizania latifolia. Int. J. Biol. Macromol. 2017, 95, 809-817. [CrossRef]

10. Yu, Y.; Shen, M.; Song, Q.; Xie, J. Biological activities and pharmaceutical applications of polysaccharide from natural resources: A review. Carbohydr. Polym. 2018, 183, 91-101. [CrossRef]

11. Li, J.; Yuan, P.; Wang, X.; Aipire, A.; Li, M.; Yang, J.; Tao, H.; Ying, T.; Fu, C.; Wei, X.; et al. Purification, characterization and bioactivities of polysaccharides from Pleurotus ferulae. Food Funct. 2017, 8, 1905-1914. [CrossRef] [PubMed]

12. Andrade, L.A.; Nunes, C.A.; Pereira, J. Relationship between the chemical components of taro rhizome mucilage and its emulsifying property. Food Chem. 2015, 178, 331-338. [CrossRef] [PubMed]

13. Chen, Y.; Li, H.; Li, M.; Niu, S.; Wang, J.; Shao, H.; Li, T.; Wang, H. Salvia miltiorrhiza polysaccharide activates $\mathrm{T}$ Lymphocytes of cancer patients through activation of TLRs mediated -MAPK and -NF-кB signaling pathways. J. Ethnopharmacol. 2017, 200, 165-173. [CrossRef] [PubMed]

14. Gan, F.; Liu, Q.; Liu, Y.; Huang, D.; Pan, C.; Song, S.; Huang, K. Lycium barbarum polysaccharides improve CCl4-induced liver fibrosis, inflammatory response and TLRs/NF-kB signaling pathway expression in wistar rats. Life Sci. 2018, 192, 205-212. [CrossRef]

15. Li, C.; Li, X.; You, L.; Fu, X.; Liu, R.H. Fractionation, preliminary structural characterization and bioactivities of polysaccharides from Sargassum pallidum. Carbohydr. Polym. 2017, 155, 261-270. [CrossRef]

16. Cheng, A.; Wan, F.; Wang, J.; Jin, Z.; Xu, X. Macrophage immunomodulatory activity of polysaccharides isolated from Glycyrrhiza uralensis Fish. Int. Immunopharmacol. 2008, 8, 43-50. [CrossRef]

17. Zhang, X.; Zhao, S.; Song, X.; Jia, J.; Zhang, Z.; Zhou, H.; Fu, H.; Cui, H.; Hu, S.; Fang, M.; et al. Inhibition effect of glycyrrhiza polysaccharide (GCP) on tumor growth through regulation of the gut microbiota composition. J. Pharmacol. Sci. 2018, 137, 324-332. [CrossRef]

18. Wu, Y.; Yi, L.; Li, E.; Li, Y.; Lu, Y.; Wang, P.; Zhou, H.; Liu, J.; Hu, Y.; Wang, D. Optimization of Glycyrrhiza polysaccharide liposome by response surface methodology and its immune activities. Int. J. Biol. Macromol. 2017, 102, 68-75. [CrossRef] 
19. Tao, W.; Duan, J.; Zhao, R.; Li, X.; Yan, H.; Li, J.; Guo, S.; Yang, N.; Tang, Y. Comparison of three officinal Chinese pharmacopoeia species of Glycyrrhiza based on separation and quantification of triterpene saponins and chemometrics analysis. Food Chem. 2013, 141, 1681-1689. [CrossRef]

20. Song, W.; Si, L.; Ji, S.; Wang, H.; Fang, X.M.; Yu, L.Y.; Li, R.Y.; Liang, L.N.; Zhou, D.; Ye, M. Uralsaponins M-Y, antiviral triterpenoid saponins from the roots of Glycyrrhiza uralensis. J. Nat. Prod. 2014, 77, 1632-1643. [CrossRef]

21. Tang, Z.H.; Li, T.; Tong, Y.G.; Chen, X.J.; Chen, X.P.; Wang, Y.T.; Lu, J.J. A Systematic Review of the Anticancer Properties of Compounds Isolated from Licorice (Gancao). Planta Med. 2015, 81, 1670-1687. [CrossRef] [PubMed]

22. Fu, Y.; Chen, J.; Li, Y.J.; Zheng, Y.F.; Li, P. Antioxidant and anti-inflammatory activities of six flavonoids separated from licorice. Food Chem. 2013, 141, 1063-1071. [CrossRef] [PubMed]

23. Aipire, A.; Li, J.; Yuan, P.; He, J.; Hu, Y.; Liu, L.; Feng, X.; Li, Y.; Zhang, F.; Yang, J.; et al. Glycyrrhiza uralensis water extract enhances dendritic cell maturation and antitumor efficacy of HPV dendritic cell-based vaccine. Sci. Rep. 2017, 7, 43796. [CrossRef]

24. Dubois, M.; Gilles, K.A.; Hamilton, J.K.; Rebers, P.A.; Smith, F. Colorimetric Method for Determination of Sugars and Related Substances. Anal. Chem. 1956, 28, 350-356. [CrossRef]

25. Dodgson, K.S.; Price, R.G. A note on the determination of the ester sulphate content of sulphated polysaccharides. Biochem. J. 1962, 84, 106-110. [CrossRef] [PubMed]

26. Ren, Y.; Zheng, G.; You, L.; Wen, L.; Li, C.; Fu, X.; Zhou, L. Structural characterization and macrophage immunomodulatory activity of a polysaccharide isolated from Gracilaria lemaneiformis. J. Funct. Foods 2017, 33, 286-296. [CrossRef]

27. Tu, W.; Zhu, J.; Bi, S.; Chen, D.; Song, L.; Wang, L.; Zi, J.; Yu, R. Isolation, characterization and bioactivities of a new polysaccharide from Annona squamosa and its sulfated derivative. Carbohydr. Polym. 2016, 152, 287-296. [CrossRef]

28. Li, J.; Wang, X.; Wang, W.; Luo, J.; Aipire, A.; Li, J.; Zhang, F. Pleurotus ferulae water extract enhances the maturation and function of murine bone marrow-derived dendritic cells through TLR4 signaling pathway. Vaccine 2015, 33, 1923-1933. [CrossRef]

29. Liu, D.; Sun, Q.; Xu, J.; Li, N.; Lin, J.; Chen, S.; Li, F. Purification, characterization, and bioactivities of a polysaccharide from mycelial fermentation of Bjerkandera fumosa. Carbohydr. Polym. 2017, 167, 115-122. [CrossRef]

30. Zhang, C.H.; Yu, Y.; Liang, Y.Z.; Chen, X.Q. Purification, partial characterization and antioxidant activity of polysaccharides from Glycyrrhiza uralensis. Int. J. Biol. Macromol. 2015, 79, 681-686. [CrossRef]

31. Wang, Y.; Li, Y.; Ma, X.; Ren, H.; Fan, W.; Leng, F.; Yang, M.; Wang, X. Extraction, purification, and bioactivities analyses of polysaccharides from Glycyrrhiza uralensis. Ind. Crops Prod. 2018, 122, 596-608. [CrossRef]

32. Chylińska, M.; Szymańska-Chargot, M.; Zdunek, A. FT-IR and FT-Raman characterization of non-cellulosic polysaccharides fractions isolated from plant cell wall. Carbohydr. Polym. 2016, 154, 48-54. [CrossRef] [PubMed]

33. Zhang, L.; Hu, Y.; Duan, X.; Tang, T.; Shen, Y.; Hu, B.; Liu, A.; Chen, H.; Li, C.; Liu, Y. Characterization and antioxidant activities of polysaccharides from thirteen boletus mushrooms. Int. J. Biol. Macromol. 2018, 113, 1-7. [CrossRef] [PubMed]

34. Jiang, Y.; Zi, W.; Pei, Z.; Liu, S. Characterization of polysaccharides and their antioxidant properties from Plumula nelumbinis. Saudi. Pharm. J. 2018, 26, 656-664. [CrossRef] [PubMed]

35. Li, H.; Dong, Z.; Liu, X.; Chen, H.; Lai, F.; Zhang, M. Structure characterization of two novel polysaccharides from Colocasia esculenta (taro) and a comparative study of their immunomodulatory activities. J. Funct. Foods 2018, 42, 47-57. [CrossRef]

36. Sun, Y.; Gong, G.; Guo, Y.; Wang, Z.; Song, S.; Zhu, B.; Zhao, L.; Jiang, J. Purification, structural features and immunostimulatory activity of novel polysaccharides from Caulerpa lentillifera. Int. J. Biol. Macromol. 2018, 108, 314-323. [CrossRef]

37. Liu, N.; Dong, Z.; Zhu, X.; Xu, H.; Zhao, Z. Characterization and protective effect of Polygonatum sibiricum polysaccharide against cyclophosphamide-induced immunosuppression in Balb/c mice. Int. J. Biol. Macromol. 2018, 107 Pt A, 796-802. [CrossRef]

38. Liu, J.; Shang, F.; Yang, Z.; Wu, M.; Zhao, J. Structural analysis of a homogeneous polysaccharide from Achatina fulica. Int. J. Biol. Macromol. 2017, 98, 786-792. [CrossRef] 
39. Xu, Y.; Gao, Y.; Liu, F.; Niu, X.; Wang, L.; Li, X.; Chen, H.; Yang, Y. Sulfated modification of the polysaccharides from blackcurrant and their antioxidant and $\alpha$-amylase inhibitory activities. Int. J. Biol. Macromol. 2018, 109, 1344-1354. [CrossRef]

40. Anand, J.; Sathuvan, M.; Babu, G.V.; Sakthivel, M.; Palani, P.; Nagaraj, S. Bioactive potential and composition analysis of sulfated polysaccharide from Acanthophora spicifera (Vahl) Borgeson. Int. J. Biol. Macromol. 2018, 111, 1238-1244. [CrossRef]

41. Liang, L.; Ao, L.; Ma, T.; Ni, Y.; Liao, X.; Hu, X.; Song, Y. Sulfated modification and anticoagulant activity of pumpkin (Cucurbita pepo, Lady Godiva) polysaccharide. Int. J. Biol. Macromol. 2018, 106, 447-455. [CrossRef]

42. Li, S.; Li, M.; Yue, H.; Zhou, L.; Huang, L.; Du, Z.; Ding, K. Structural elucidation of a pectic polysaccharide from Fructus Mori and its bioactivity on intestinal bacteria strains. Carbohydr. Polym. 2018, 186, 168-175. [CrossRef] [PubMed]

43. Cai, L.; Zou, S.; Liang, D.; Luan, L. Structural characterization, antioxidant and hepatoprotective activities of polysaccharides from Sophorae tonkinensis Radix. Carbohydr. Polym. 2018, 184, 354-365. [CrossRef] [PubMed]

44. Zhang, C.; Chen, H.; Bai, W. Characterization of Momordica charantia L. polysaccharide and its protective effect on pancreatic cells injury in STZ-induced diabetic mice. Int. J. Biol. Macromol. 2018, 115, 45-52. [CrossRef] [PubMed]

45. Li, Q.; Zhang, F.; Chen, G.; Chen, Y.; Zhang, W.; Mao, G.; Zhao, T.; Zhang, M.; Yang, L.; Wu, X. Purification, characterization and immunomodulatory activity of a novel polysaccharide from Grifola frondosa. Int. J. Biol. Macromol. 2018, 111, 1293-1303. [CrossRef] [PubMed]

46. Chen, J.; Li, W.C.; Gu, X.L. Optimized Extraction, Preliminary Characterization, and In Vitro Antioxidant Activity of Polysaccharides from Glycyrrhiza uralensis Fisch. Med. Sci. Monit. 2017, 23, 1783-1791. [CrossRef] [PubMed]

(C) 2020 by the authors. Licensee MDPI, Basel, Switzerland. This article is an open access article distributed under the terms and conditions of the Creative Commons Attribution (CC BY) license (http://creativecommons.org/licenses/by/4.0/). 